\title{
Nickel-Catalyzed Olefination of Unactivated Aliphatic Dithioacetals
}

\author{
Li-Fu Huang, ${ }^{\dagger} \S$ Chih-Hao Huang, ${ }^{\dagger}$ Baldur Stulgies,${ }^{\S} \perp$ Armin de Meijere, ${ }^{\perp}$ and \\ Tien-Yau Luh*,t,f,\$
}

Department of Chemistry and Institute of Polymer Science and Engineering, National Taiwan University, Taipei, Taiwan 106, Institute of Chemistry, Academia Sinica, Nangang, Taipei, Taiwan 115, and Institut für Organische Chemie, Georg-August-Universität Göttingen, Tammannstrasse 2, 37077 Göttingen, Germany

tyluh@chem.sinica.edu.tw

Received September 18, 2003

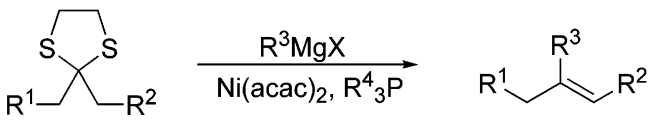

Olefination of aliphatic dithioacetals with Grignard reagents is catalyzed by $\mathrm{Ni}(\mathrm{acac})_{2}$ in the presence of an appropriate trialkylphosphine ligand.

There has been an increasing interest in the transition-metalcatalyzed cross coupling of aliphatic halides or related electrophiles with nucleophiles. ${ }^{1-4}$ The use of electron-rich aliphatic phosphine ligands, inter alia, has provided a powerful access to these coupling reactions. ${ }^{2}$ We have extensively studied the nickel-catalyzed cross-coupling reactions of benzylic or allylic dithioacetals with Grignard reagents. ${ }^{5,6}$ In the absence of an auxiliary chelating group $(s)^{6}$ or specially de-

\footnotetext{
$\pitchfork$ Department of Chemistry, National Taiwan University.

$\doteqdot$ Institute of Polymer Science and Engineering, National Taiwan University.

$\S$ Institute of Chemistry, Academia Sinica.

${ }^{\perp}$ Institut für Organische Chemie, Georg-August-Universität Göttingen.

(1) (a) For reviews, see: Leung, M.-K.; Wong, K.-T.; Luh, T.-Y. Chem. Rev. 2000, 100, 3187-3204. (b) Cardenas, D. J. Angew. Chem., Int. Ed. 2003, 42, 384-387.

(2) (a) Netherton, M. R.; Dai, C.; Neuschütz, K.; Fu, G. C. J. Am. Chem. Soc. 2001, 123, 10099-10100. (b) Kirchhoff, J. H.; Netherton, M. R.; Hills, I. D.; Fu, G. C. J. Am. Chem. Soc. 2002, 124, 13662-13663. (c) Kirchhoff, J. H.; Dai, C.; Fu, G. C. Angew. Chem., Int. Ed. 2002, 41, 1945-1947. (d) Netherton, M. R.; Fu, G. C. Angew. Chem., Int. Ed. 2002, 41, 3910-3912. (e) Frisch, A. C.; Shaikh, N.; Zapf, A.; Beller, M. Angew. Chem., Int. Ed. 2002, 41, 4056-4059. (f) Menzel, K.; Fu, G. C. J. Am. Chem. Soc. 2003, 125, 3718-3719. (g) Lee, J. Y.; Fu, G. C. J. Am. Chem. Soc. 2003, 125, 5616-5617.

(3) (a) Boudier, A.; Bromm, L. O.; Lotz, M.; Knochel, P. Angew. Chem. Int. Ed. 2000, 39, 4414-4435. (b) Dohle, W.; Lindsay, D. M.; Knochel, P. Org. Lett. 2001, 3, 2871-2873. (c) Jensen, A. E.; Knochel, P. J. Org. Chem. 2002, 67, 79-85. (d) Wolter, M.; Nordmann, G.; Job, G. E.; Buchwald, S. L. Org. Lett. 2002, 4, 973-976. (e) Lei, A.; Zhang, X. Org. Lett. 2002, 4, 2285-2288. (f) Terao, J.; Watanabe, H.; Ikumi, A.; Kuniyasu, H.; Kambe, N. J. Am. Chem. Soc. 2002, 124, 4222-4223.

(4) Ni, Z.-J.; Mei, N.-W.; Shi X.; Tzeng, Y.-L.; Wang, M.-C.; Luh, T.Y. J. Org. Chem. 1991, 56, 4035-4042.
}

signed substrates, ${ }^{7}$ aliphatic dithioacetals alone do not react with Grignard reagents, even in the presence of the typical nickel triarylphosphine catalyst. We envisaged that an increase of the nucleophilicity of the nickel catalyst by incorporation of a trialkylphosphine ligand might enhance the reactivity of the catalytic center toward the oxidative addition across the carbon-sulfur bond, and we now wish to document the first examples of such a nickel-catalyzed olefination of unactivated aliphatic dithioacetals with Grignard reagents.

In the beginning of this work, we examined the performance of different kinds of trialkylphosphine ligands in the olefination reaction of $\mathbf{1}$ with the Grignard reagent. Thus, treatment of 2-(2'-naphthyl)acetaldehyde dithioacetal 1 with 3 equiv of $\mathrm{MeMgI}$ in the presence of $5 \mathrm{~mol} \%$ of $\mathrm{Ni}(\mathrm{acac})_{2}$ and $12 \mathrm{~mol} \%$ of trialkylphosphine in refluxing toluene for $20 \mathrm{~h}$ afforded a mixture of the naphthyl derivatives $\mathbf{2 - 4}$ (eq 1). The results are summarized in Table 1.

The reaction may proceed according to a mechanism similar to the one proposed for the benzylic substrates. ${ }^{5,6}$ The two carbon-sulfur bonds in $\mathbf{1}$ may be cleaved at different stages and the overall reaction may involve a coupling process followed by an elimination step. The organonickel intermediate $\mathbf{5}$ would be expected to undergo nonselective

(5) Luh, T.-Y. Acc. Chem. Res. 1991, 24, 257-263.

(6) (a) Wong, K.-T.; Yuan, T.-M.; Wang, M.-C.; Tung, H.-H.; Luh, T.Y. J. Am. Chem. Soc. 1994, 116, 8920-8929. (b) Luh, T.-Y. Synlett 1996 201-208.

(7) Cheng, W.-L.; Luh, T.-Y. Chem. Commun. 1992, 1392-1393. 
Table 1. Ni(acac $)_{2}$-Catalyzed Olefination of $\mathbf{1}$ in the Presence of Trialkylphosphine Ligand

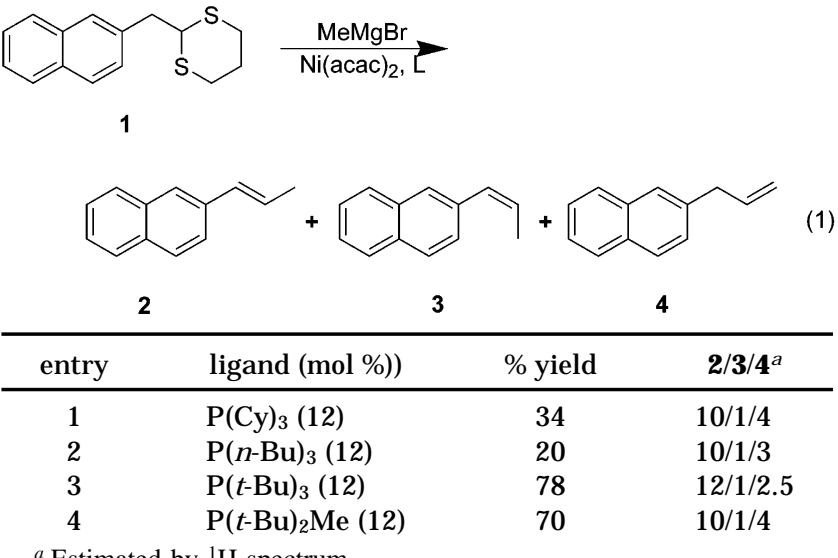

${ }^{a}$ Estimated by ${ }^{1} \mathrm{H}$ spectrum.

$\beta$-hydride elimination giving a mixture of $\mathbf{2 - 4}$. Although the product distributions were not much affected by the nature of the trialkylphosphine ligands, phosphines with a large cone angle may cause higher reactivity in these olefination reactions, and indeed, the best yield was obtained when $\mathrm{P}^{\prime} \mathrm{Bu}_{3}$ was used.

When 1 was treated with $\mathrm{TMSCH}_{2} \mathrm{MgCl}$ in the presence of $5 \mathrm{~mol} \%$ of $\mathrm{Ni}(\mathrm{acac})_{2}$ and $12 \mathrm{~mol} \%$ of $\mathrm{P}^{t} \mathrm{Bu}_{3}$ under the same conditions as just described, allylsilane $\mathbf{6}$ was obtained in 57\% yield. Interestingly, only a trace amount of vinylsilane 7 was detected, which was easily removed from 6 by recrystallization. Vinylsilane 9 was obtained in $91 \%$ yield from the nickel-catalyzed reaction of $\mathbf{8}$ with $\mathrm{PhMe}_{2} \mathrm{SiCH}_{2-}$ $\mathrm{MgCl}$ under the same conditions. In a similar manner, reaction of $\mathbf{1 0}$ with $\mathrm{PhMgBr}$ afforded $\mathbf{1 1}$ (containing a trace amount of the cis isomer) in 50\% yield. Apparently, the ring size of the dithioacetal moiety does not have any influence on the reactivity under these olefination conditions.

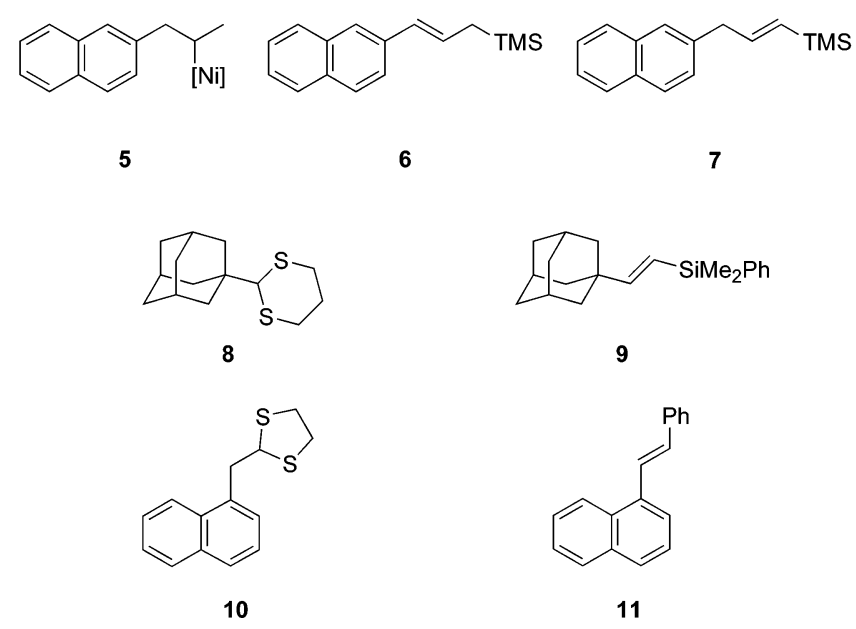

Ketone dithioacetals also reacted smoothly under similar conditions. Again, the nature of the ligand does influence the yield of the reaction. Thus, nickel-catalyzed reaction of cyclohexanone dithioacetal 12 with $\mathrm{PhMgBr}$ afforded 13 in $48 \%$ yield when $\mathrm{P}^{t} \mathrm{Bu}_{3}$ was employed as the ligand. The yield

of 13 improved to $56 \%$ when $\mathrm{P}^{t} \mathrm{Bu}_{2} \mathrm{Me}$ was used. Similarly, the cyclododecanone derivative $\mathbf{1 5}$ was transformed into the corresponding olefination product $\mathbf{1 6}(E / Z=10 / 1)$ in $52 \%$ and $67 \%$ yields, respectively, under the same conditions with $\mathrm{P}^{t} \mathrm{Bu}_{3}$ and $\mathrm{P}^{t} \mathrm{Bu}_{2} \mathrm{Me}$ as the ligand. Since ketone dithioacetals in general are more sterically congested than aldehyde dithioacetals, a less bulky ligand may provide a more spacious environment to lead to the desired coupling product. Thus, by using $\mathrm{P}^{\prime} \mathrm{Bu}_{2} \mathrm{Me}$ as the ligand, the $\mathrm{Ni}(\mathrm{acac})_{2}$-catalyzed reactions of 12 and $\mathbf{1 5}$ with $4-\mathrm{MeC}_{6} \mathrm{H}_{4} \mathrm{MgBr}$ afforded $\mathbf{1 4}$ and $\mathbf{1 7}$ in 59\% and 63\% yields, respectively. Dithioacetals derived from acyclic ketones behaved similarly. Treatment of $\mathbf{1 8}$ with $\mathrm{PhMgBr}$ under the same conditions, with $\mathrm{P}^{t} \mathrm{Bu}_{2} \mathrm{Me}$ as the ligand, gave the corresponding olefination product 19 in $61 \%$ yield. Olefin 20 was isolated in 55\% yield from a similar reaction of $\mathbf{1 8}$ with $4-\mathrm{MeC}_{6} \mathrm{H}_{4} \mathrm{MgBr}$. Aliphatic Grignard reagent also reacted smoothly. For example, treatment of $\mathbf{2 1}$ with $\mathrm{Me}_{3} \mathrm{SiCH}_{2} \mathrm{MgCl}$ afforded the corresponding vinylsilane 22 in $73 \%$ yield by using the same procedure.

In summary, we have demonstrated the first example of the nickel-catalyzed cross-coupling reaction of the aliphatic dithioacetals derived from aldehydes and ketones with Grignard reagents. Our results document an additional application of trialkylphosphines to assist the activation of otherwise unactivated aliphatic carbon-sulfur bonds in the nickel-catalyzed cross-coupling reaction. The reaction may provide a useful procedure for a direct conversion of a dithioacetal-protected carbonyl group into the corresponding olefins. In particular, vinylsilanes are conveniently obtained by this route. Further investigation to improve the regioslectivity in the formation of the new double bond is in progress in our laboratory.

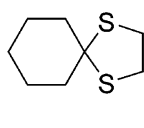

12

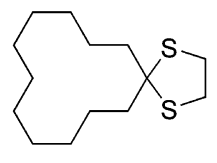

15

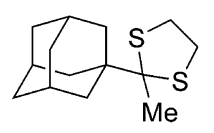

18

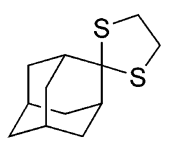

21
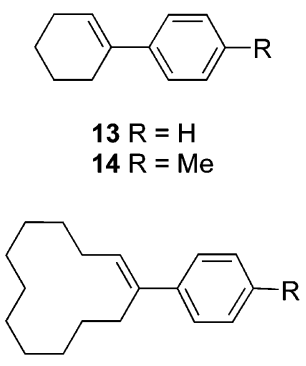

$16 \mathrm{R}=\mathrm{H}$

$17 \mathrm{R}=\mathrm{Me}$

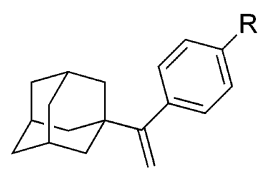

$19 \mathrm{R}=\mathrm{H}$

$20 \mathrm{R}=\mathrm{Me}$

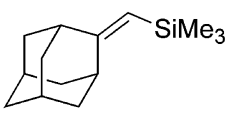

22 
Acknowledgment. We thank the National Science Council and the Ministry of Education of the Republic of China for financial support. We also thank the PPP exchange program cosponsored by the NSC (Taiwan) and the DAAD (Germany) to enable B.S. to do part of the experimental work at the Academia Sinica.
Supporting Information Available: Experimental details of the nickel-catalyzed reactions of dithioacetals with Grignard reagents. This material is available free of charge via the Internet at http://pubs.acs.org.

OL035802O 